\title{
Comparative antidiabetic activity of methanolic extract of Operculina turpethum stem and root against healthy and streptozotocin induced diabetic rats
}

\author{
*Shankaraiah Pulipaka', Srinivasa Reddy Challa², Ravindra Babu Pingili ${ }^{3}$ \\ ${ }^{1}$ Trinity College of Pharmaceutical Sciences, Peddapally, Karimnagar, Andhra Pradesh, India, 505172 \\ ${ }^{2}$ Vaagdevi College of Pharmacy, Hanamkonda, Warangal, Andhra Pradesh, India, 506001 \\ ${ }^{3}$ KVSR Siddhartha College of Pharmaceutical Sciences, Department of Pharmacology, Vijayawada, Andhra Pradesh, India, 520010
}

\begin{abstract}
Diabetes mellitus (DM) consists of a group of syndromes characterized by hyperglycemia. Prevalence of both type 1 and type $2 \mathrm{DM}$ is increasing worldwide, the prevalence of type 2 is rising much more rapidly because of increasing obesity and reduced activity levels as countries become more industrialized. Operculina turpethum, a medicinal plant widely used in the traditional Ayurveda and Siddha systems of medicine for the treatment of diabetes mellitus. The antidiabetic potential of the methanolic extract of O. turpethum stem (MEOTS) and methanolic extract of O. turpethum root (MEOTR) was evaluated in the Streptozotocin (STZ) - induced type 2 diabetic models. The dose $100 \mathrm{mg} / \mathrm{kg}$ of MEOTS and MEOTR were administered to normal, glucose loaded and experimental diabetic rats for 21 days. The significantly $(\mathrm{p}<0.05)$ reduction in fasting blood glucose levels were observed in the normal rats at $3 \mathrm{~h}$ as well as in the treated diabetic animals at 21 days, thereby justifying the use of the plant in the indigenous system of medicine.
\end{abstract}

Key Words: Operculina turpethum, Type 2 diabetes, Streptozotocin, Glibenclamide, Insulin, Convolvulaceae.

\section{INTRODUCTION}

Diabetic mellitus (DM) is the condition arising due to abnormal metabolism of carbohydrate, proteins and fats. It is caused by insulin deficiency, often combined with insulin resistance. This disorder occurs worldwide and its occurrence is increasing quickly in most of the countries. Various complications develop as a consequence of the metabolic derangement in diabetes. The treatment of DM is based on parenteral insulin and oral anti-diabetic drugs. Oral hypoglycemic agents, currently used have serious side effect hence there is a need to search a newer anti-diabetic agents that having high therapeutic efficacy with minimum side effect (Holman, 1991). This may be fulfilled by treating DM with traditional medicine using as anti-diabetic agents from medicinal plants. Diabetes mellitus (DM) consists of a group of syndromes characterized by hyperglycemia; altered metabolism of

\footnotetext{
*Corresponding Author:

Shankaraiah Pulipaka, Assistant Professor

Trinity College of Pharmaceutical Sciences

Peddapally, Karimnagar

Andhra Pradesh, India, 505172.

E-mail: shankar.pulipaka@gmail.com

Contact No.: +91- 9885589543
}

lipids, carbohydrates, and proteins; and an increased risk of complications from vascular disease. The worldwide prevalence of DM has raisen dramatically over the past two decades, from an estimated 30 million cases in 1985 to 177 million in 2000. Based on the current trends $>360$ million individuals will have diabetes by the year 2030 (Harisons, 2007).

Plants have always been an exemplary source of drugs and many of the currently available drugs have been derived directly or indirectly from them. The ethnobotanical information reports about 800 plants that may possess anti-diabetic potential. Several such herbs have shown anti-diabetic activity when assessed using presently available experimental techniques. A wide array of plant derived active principles representing numerous chemical compounds has demonstrated activity consistent with their possible use in the treatment of NIDDM. Among these are alkaloids, glycosides, galactomannan gum, polysaccharides, peptidoglycans, hypoglycans, guanidine, steroids, carbohydrates, glycopeptides, terpenoids, amino acids and inorganic ions. Even the discovery of widely used hypoglycemic drug, metformin came from the 
traditional approach of using Galega officinalis (Grover et al., 2002). Thus, plants are a potential source of anti-diabetic drugs (and others too) but this fact has not gained enough momentum in the scientific community. The reasons may be many including lack of belief among the practitioners of conventional medicine over alternative medicine, alternative forms of medicine are not very welldefined, possibility of quacks practicing such medicine providing alluring and magical cures and natural drugs may vary tremendously in content, quality and safety. Although, oral hypoglycemic agents/insulin is the mainstay of treatment of diabetes and is effective in controlling hyperglycemia, they have prominent side effects and fail to significantly alter the course of diabetic complications (Rang, 1991). As the knowledge of heterogeneity of this disorder increases, there is needed to look for more efficacious agents with lesser side effects. Though development of modern medicine resulted in the advent of modern pharmacotherapeutics including insulin, biguanides, sulfonylurea's and thiazolidinediones, there is still a need to look for new drugs as no drug (except strict glycemic control with insulin) has been shown to modify the course of diabetic complications. In relation to plants also, barring a few studies. Most of the studies have not assessed the impact of these plants on the course of diabetic complications (Grover et al., 2000).

In the modernized world, the changes in dietary habits and life style of the people leading to the cause of Non-communicable diseases. The Noncommunicable diseases such as heart diseases, strokes, diabetes, cancer \& lung diseases, account for nearly $60 \%$ of deaths globally. Among the Noncommunicable disease, diabetes mellitus is affecting nearly $10 \%$ of population all over the world. The global prevalence of the disease is increasing day by day and is estimated that, it would increase to 300 million by 2025 . The prevalence of diabetes in India is reported to be $2-4 \%$ in rural and $4-11 \%$ in urban dwellers. It is projected that India would become the world capital of diabetes mellitus within a span of 10 years.

Though various drugs are available in different systems of medicine for management of diabetes, no drug either synthetic (or) herbal gives permanent relief to the disorders, further the regular use of these drugs. Mainly synthetic drugs causing damage to the vital organs such as heart, liver, kidney etc. thus herbal products is growing exponentially. In view of this, extensive research work is going on medicinal plants throughout the world, to develop novel anti diabetic drugs with high therapeutic efficacy and devoid of side effects. However, it is currently a challenge to the researchers of all the systems of medicine for developing novel antidiabetic drugs (Abaira et al., 1995).

Operculina turpethum is a perennial with milky juice belongs to family Convolvulaceae. This plant was widespread in old tropics from E. Africa to $\mathrm{N}$. Australia, this plant common in Godavari, Andhra Pradesh, India. It is widely distributed in tropical Africa and Asia. In India it is found in damp and it occurs almost throughout India up to an altitude of about $1000 \mathrm{~m}$. It is sometimes grown in gardens for its beautiful flowers. It is rare on open sandy soils. It is occasionally cultivated in India (John and Parrotta, 2005).

Traditionally, Operculina turpethum root is prescribed in the treatment of snake bite (sushruta and vrindamadhava) and scorpion sting (sushruta), but it is not an antidote to either snake-venom (Mhaskar and Caius) or scorpion-venom (Caius and Mhaskar). In constipation, it is an effective laxative. It is used in periodic fevers and in the treatment of anemia accompanied by spenomegaly. It is also used to relieve flatulence and colic and in the treatment of obesity to decrease fat. It is used to treat dropsy, dyspepsia with constipation and flatulence, gout and rheumatism, and other inflammations (Suresh Kumar et al., 2006). In the present study, stem and root methanolic extract was used to study hypoglycemic activity in normal and diabetic rats.

The root extract of Operculina turpethum has been used as an anti-inflammatory, purgative, and hepatoprotective agent (Riaz, 2009). Ethereal, alcoholic and aqueous extracts of roots of ipomoea turpethum (Nishoth) have been screened for their anti- inflammatory activity (Khare et al., 1982).

The root of Operculina turpethum is the chief ingredient in the Ayurvedic formulation viz. Avipattikarachurna used for the treatment of gastric 
Table 1: Effect of MEOTS and MEOTR on glucose levels in glucose loaded rats $(n=6)$.

\begin{tabular}{cllll}
\hline $\begin{array}{c}\text { Time } \\
\text { (Min) }\end{array}$ & Group I & Group II & Group III & Group IV \\
\hline 0 & $98 \pm 3.31$ & $91 \pm 4.54$ & $92 \pm 3.60$ & $90 \pm 4.12$ \\
30 & $169 \pm 2.28$ & $140 \pm 2.52^{*}$ & $146 \pm 5.48^{*}$ & $157 \pm 3.43^{*}$ \\
60 & $155 \pm 5.02$ & $121 \pm 6.41^{*}$ & $127 \pm 4.57^{*}$ & $131 \pm 5.65^{*}$ \\
120 & $146 \pm 5.45$ & $96 \pm 4.05^{*}$ & $107 \pm 6.15^{*}$ & $97 \pm 5.50^{*}$ \\
\hline
\end{tabular}

ulcer and related gastrointestinal disturbances (Rajashekar et al., 2006). Antioxidant activity of methanolic extract of Operculina turpethum stems (Anbuselvam et al., 2007). The chloroform extract of stem of Ipomoea turpethum and the crude petroleum ether, chloroform and ethylacetate extracts were screened against thirteen pathogenic bacteria for their antibacterial activities (Harun et al., 2002). It is reported to be highly medicinal and is cultivated occasionally in gardens as an ornamental plant. Some hydroxy fatty acids, butulin, lupeol and sitosterol have been found in the plant. Seed gums are important vegetable products used in various industries like paper, textile, cosmetics, food and pharmaceuticals (Jain, 1977).

\section{MATERIALS AND METHODS}

\section{Drugs and chemicals}

Streptozotocin was purchased from Sigma Aldrich chemicals Pvt. Ltd., USA. Glibenclamide was obtained as a gift sample from Sanofi Aventis India Ltd. Glucometer (Bayer Health Care, Japan) purchased from local pharmacy. All other chemicals and reagents used were of analytical grade.

\section{Collection of plant material}

Operculina turpethum (L.) Silva Manso plant material was collected from local areas of Vijayawada, Andhra Pradesh, India. The herbarium was maintained in the Department of Pharmacognosy and phytochemistry, Vaagdevi College of Pharmacy, Hanamkonda. Operculina turpethum stem and root was washed under tap water and were efficiently dried under shade for about one week and protected from deterioration. The shade dried stem was grinded made into powder with the help of a laboratory mixer. These were efficiently dried under shade for
Table 2: Effect of MEOTS and MEOTR on blood glucose of healthy rats $(n=6)$.

\begin{tabular}{cclll}
\hline $\begin{array}{c}\text { Time } \\
\text { (Min) }\end{array}$ & Group I & Group II & Group III & Group IV \\
\hline 0 & $80 \pm 2.7$ & $77 \pm 3.5$ & $76 \pm 2.8$ & $81 \pm 4.6$ \\
30 & $76 \pm 3.4$ & $70 \pm 4.7$ & $72 \pm 4.6^{*}$ & $75 \pm 4.8^{*}$ \\
60 & $74 \pm 2.8$ & $64 \pm 3.4^{*}$ & $66 \pm 4.0^{*}$ & $71 \pm 2.4^{*}$ \\
120 & $73 \pm 3.3$ & $58 \pm 4.6^{*}$ & $63 \pm 3.5^{*}$ & $67 \pm 3.6^{*}$ \\
\hline
\end{tabular}

* $(\mathrm{p}<0.01)$ when compared to control

about one week and protected from deterioration and then grinded and made into powder.

\section{Preparation of extract}

The chemical compounds were extracted from the stem and root using successive solvent extraction process (soxhlation apparatus). The stem and root powder $(100 \mathrm{~g})$ was extracted with methanol for 6 hours. After completion of soxhlation process the liquid extract was collected and concentrated under reduced pressure below $50^{\circ} \mathrm{C}$, until a soft mass obtained it was dried and kept in a desiccator.

Preliminary phytochemical screening (The Ayurvedic pharmacopoeia of India, 2001)

The extracts were preliminary investigated for various phytochemical constituents such as alkaloids, Carbohydrates, Steroids, Proteins, Phenols, Tannins, Flavonoids, Glycosides, Gums, Saponins and terpenes. A spectrum of natural compounds like alkaloids, glycosides, tannins, essential oils and similar other secondary metabolites which exert physiological activity are synthesized in the plant, in addition to the carbohydrates, proteins and lipids utilized by man as food articles.

A systematic and complete study of crude drugs should include an investigation of both primary and secondary metabolites derived as a result of plant metabolism. The different qualitative chemical tests are to be performed for establishing profile of a given extract for its nature of chemical composition. Qualitative phytochemical screening was carried out for the presence of various phytochemicals in the obtained extracts

\section{Preparation of standard drug}

Glibenclamide was suspended in $0.5 \%$ Sodium Carboxy Methyl Cellulose (SCMC). 


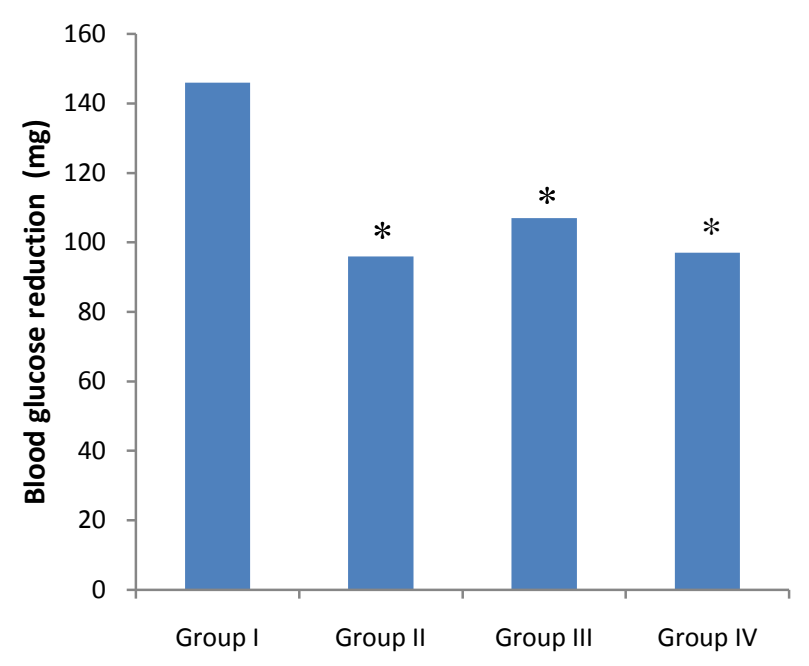

Figure 1: Effect of MEOTS and MEOTR on glucose levels in glucose loaded rats at $\mathbf{1 2 0} \mathrm{min}(\mathrm{n}=\mathbf{6})$.

${ }^{*}(\mathrm{p}<0.01)$ when compared to control

\section{Experimental design}

The antidiabetic activity of MEOTS and MEOTR was assessed in normal, glucose loaded and STZ induced diabetic rats. In all studies, the animals were fasted overnight for $16 \mathrm{~h}$ with free access to water throughout the duration of the experiment.

\section{Animals used}

Experiments were performed with male wistar rats procured from Mahaveera enterprises (Hyderabad, Andhra Pradesh, India), weighing about 180-220 g. The animals were housed in individual polypropylene cages under standard laboratory conditions of light, temperature $\left(22 \pm 1^{\circ} \mathrm{C}\right)$ and relative humidity for at least one week before the beginning of experiment, to adjust to the new environment and to overcome stress possibly incurred during transit. Animals were given standard rat pellets and drinking water ad libitum. The animals were fasted 12 hours before the conduct of experiment and during the experiment they were withdrawn from food and water. The experiments were planned after the approval of Institutional Animal Ethical Committee (Approval number is 2010/8/1/1-6).

\section{Acute toxicity studies}

Acute oral toxicity study was performed as per OECD-423 guidelines (acute toxic class method). Wistar rats $(n=6)$ of either sex selected by random sampling techniques were employed in this study.

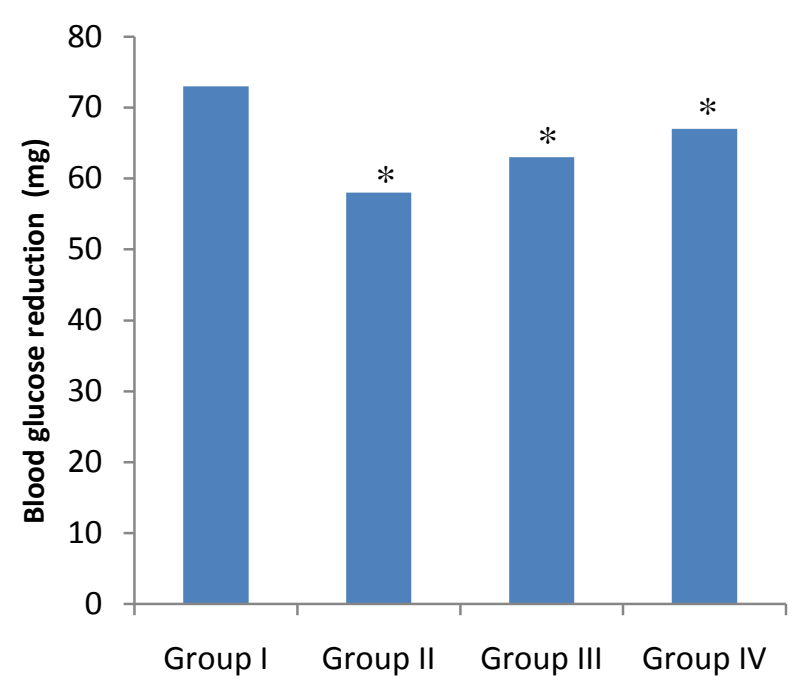

Figure 2: Effect of MEOTS and MEOTR on blood glucose of healthy rats at $120 \mathrm{~min}(n=6)$.

* $(p<0.01)$ when compared to control

The animal were kept fasting for overnight providing only water. Then the extracts (stem and roots) were administered orally at the dose of $2000 \mathrm{mg} / \mathrm{kg}$ by intragastric tube and observed for 2 days for the gross behavioral changes and mortality.

Effect of MEOTS and MEOTR on oral glucose tolerance test (Prakasam et al., 2003)

Healthy rats were divided into four groups of six animals each.

Group I served as control and treated with $0.5 \%$ sodium CMC

Groups II treated with glibenclamide $(5 \mathrm{mg} / \mathrm{kg})$

Group III treated with MEOTS $(100 \mathrm{mg} / \mathrm{kg})$

Group IV treated with MEOTR $(100 \mathrm{mg} / \mathrm{kg})$ orally. All animals were treated with glucose $(1.2 \mathrm{~g} / \mathrm{kg})$ after $30 \mathrm{~min}$ of treatment and blood samples were collected from the tail vein just prior to treatment $(0$ h) and at 30, 60, 90 and $120 \mathrm{~min}$. and blood glucose levels were estimated by glucometer.

\section{Effect of MEOTS and MEOTR on healthy rats (Kar} et al., 2006)

At the end of the fasting period, taken as zero time $(0 \mathrm{~h})$, blood was withdrawn from the tail vein and blood glucose was estimated with glucometer. The animals were then randomly divided into four groups of six animals each. 
Table 3: Effect of MEOTS and MEOTR on glucose levels of STZ- induced diabetic rats $(n=6)$.

\begin{tabular}{ccccc}
\hline $\begin{array}{c}\text { Time } \\
\text { (day) }\end{array}$ & Group I & Group II & Group III & Group IV \\
\hline 0 & $336 \pm 5.6$ & $342 \pm 7.4$ & $337 \pm 9.2$ & $355 \pm 10.3$ \\
7 & $324 \pm 4.8$ & $303 \pm 6.0^{*}$ & $310 \pm 7.5^{*}$ & $331 \pm 7.6^{*}$ \\
14 & $319 \pm 6.1$ & $268 \pm 5.3^{*}$ & $284 \pm 8.3^{*}$ & $303 \pm 8.1^{*}$ \\
21 & $311 \pm 6.1$ & $216 \pm 4.6^{*}$ & $233 \pm 5.2^{*}$ & $252 \pm 5.6^{*}$ \\
\hline
\end{tabular}

Group I served as control and treated with $0.5 \%$ sodium CMC

Groups II treated with glibenclamide $(5 \mathrm{mg} / \mathrm{kg}$ )

Group III treated with MEOTS $(100 \mathrm{mg} / \mathrm{kg})$

Group IV treated with MEOTR $(100 \mathrm{mg} / \mathrm{kg})$ orally. The blood glucose levels were determined 1, 2, 3 and $4 \mathrm{~h}$ following treatment with glucometer.

Effect of MEOTS and MEOTR in STZ - induced diabetic rats (Arulselvan et al., 2007)

\section{Induction of Diabetes Mellitus}

Experimental diabetes was induced by single intraperitoneal injection of $60 \mathrm{mg} / \mathrm{kg}$ of STZ, freshly dissolved in cold citrate buffer, $\mathrm{pH}$ 4.5. Control animals received only citrate buffer. After 5 days of STZ injection, animals with fasting blood glucose above $300 \mathrm{mg} / \mathrm{dL}$ were considered as diabetic and included in the study. No adverse effect was observed at the tested concentration throughout the study. The animals were randomly divided into four groups of six animals each and received the following treatments

Group I treated with $0.5 \%$ SCMC

Group II treated with glibenclamide $(5 \mathrm{mg} / \mathrm{kg})$

Group III treated with MEOTS $(100 \mathrm{mg} / \mathrm{kg})$

Group IV treated with MEOTR $(100 \mathrm{mg} / \mathrm{kg})$ orally daily for 21 days and blood glucose levels were estimated on $7^{\text {th }}, 14^{\text {th }}$ and $21^{\text {th }}$ day. All data expressed as mean \pm S.D and statistical analysis was performed by ANOVA.

\section{RESULTS}

Effect of MEOTS and MEOTR on glucose loaded rats

Fasting blood glucose levels were estimated in 18 hrs fasted rats in all groups. After $30 \mathrm{~min}$ of treatment glucose $(1.2 \mathrm{~g} / \mathrm{kg})$ was given. Blood glucose levels in all groups increased rapidly and gradually decreased thereafter. A significant reduction of the

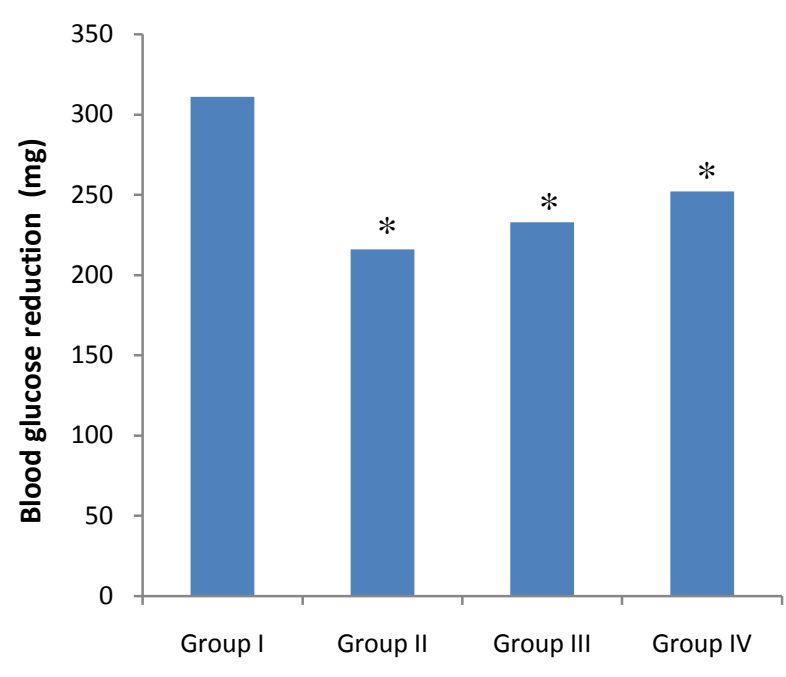

Figure 3: Effect of MEOTS and MEOTR on glucose levels of STZ- induced diabetic rats at $21^{\text {st }}$ day $(n=6)$.

rise of blood glucose levels after $60 \mathrm{~min}$ with MEOTS and MEOTR at $100 \mathrm{mg} / \mathrm{kg}$, but MEOTS produced more effect when compared to MEOT. Results were shown in Table 1 . The \% blood glucose reduction with MEOTS, MEOTR and glibenclamide in glucose loaded rats shown in Figure 1.

\section{Effect of MEOTS and MEOTR on blood glucose of healthy rats}

MEOTS and MEOTR decreased blood glucose levels in healthy rats but MEOTS produce more effect when compared with MEOTR. Results were shown in Table 2 and \% blood glucose reduction was shown in Figure 2.

\section{Effect of MEOTS and MEOTR in STZ - induced diabetic rats}

The effects of MEOTS and MEOTR on STZ-induced diabetic rats were evaluated. Diabetic rats treated with MEOTS and MEOTR (100 mg/kg/day) for 3 weeks. Figure shows the hypoglycemic effect of MEOTS and MEOTR on the \% blood glucose level of rats with STZ-induced diabetes during the experimental period. The blood glucose level in STZ rats was significantly decreased after 3 weeks. Results were shown in Table 3. In addition, for the OGTT, a significant reduction of oral glucose tolerance was observed in both groups (Figure 3). 


\section{DISCUSSION}

From the ancient time, plants are used as an essential component of traditional medicine systems (Fang et al., 2005). Still today medicinal plants remain significantly as natural alternatives to synthetic drugs with about $80 \%$ of the world population depending upon plants for their primary health care according to WHO estimation (Akerele et al., 1993) These past and current dependence on plant as a source for medicines gives impetus to the ethnopharmacological studies for studying their efficacy, safety and drug-discovery potentials. Herbal medicine plays an important role in the healthcare of many developing countries. The use of herbal products is increasing worldwide due to the distinct advantages. Herbal medicines include herbs, herbal materials, herbal preparations and finished herbal products that contain as active ingredients parts of plants, or other plant materials, or combinations (World Health Organization, 2008).

$\mathrm{DM}$ is an endocrine dysfunction resulting from insulin deficiency or incapability of peripheral tissues to respond to insulin (Singh et al., 2008). The use of traditional medicine and medicinal plants in most developing countries, as a normative basis for the maintenance of good health, has been widely observed (Tiwari et al., 2002). DM is probably the fastest growing metabolic disease in the world and as knowledge of the heterogeneous nature of the disease increases so does the need for more challenging and appropriate therapies. Traditional plant remedies have been used for centuries in the treatment of diabetes (Kesari et al., 2005), but only a few have been scientifically evaluated. Therefore, we have investigated the effect of MEOTS and MEOTR on glycemic control in healthy, glucose loaded and STZ-induced diabetic rats.

MEOTS and MEOTR significantly decreased blood glucose level in healthy rats, glucose loaded and STZ-induced diabetic rats. When compared to MEOTR, MEOTS produced more significant effect on blood glucose level. The capacity of MEOTS and MEOTR to decrease the elevated blood glucose to normal level is an essential trigger for the liver to revert to its normal homeostasis during experimental diabetes. The possible mechanism by which MEOTS and MEOTR exerts its hypoglycemic action in diabetic rats may be due to potentiating the insulin release, since the percentage fall in blood glucose levels was very significant $(p<0.05)$ at $100 \mathrm{mg} / \mathrm{kg}$.

\section{CONCLUSION}

The stem and roots of OT is a good candidate as alternative and/or complementary medicine in the management of DM. The results of the present study indicate that the MEOTS and MEOTR are capable of exhibiting significant anti-hyperglycemic activity in STZ - induced diabetic rats and hypoglycemic activity in healthy, glucose loaded rats. Continuous blood glucose monitoring is needed in diabetes patients because it produces synergistic effect with oral hypoglycemic agents. OT may be altering the pharmacokinetic of glibenclamide. The possible mechanism by which MEOTS and MEOTR exerts its hypoglycemic action in diabetic rats may be due to potentiating the insulin release, further investigations are needed to identify the lead molecule and to elucidate exact mechanism of action for antidiabetic effect.

\section{ACKNOWLEDGEMENT}

Authors are very grateful to the management of Vaagdevi College of Pharmacy, Warangal for providing necessary facilities.

\section{REFERENCES}

Abaira, C., Colwell, J.A., Nuttall, F.Q., Sawin, C.T., Nagel, N.J. (1995). Veterans Affairs Cooperative Study on glycemic control and complications in type II diabetes (VA CSDM). Results of the Feasibility trial. Veterans Affairs Cooperative Study in Type II Diabetes. Diabetes care, 18 (8): 1113-1123. [DOI]

Akerele O. (1993). Summary of WHO guidelines for the assessment of herbal medicine. Herbalgram, 28: 13-19.

Anbuselvam, C., Vijayavel, K., Balasubramanian, M. P. (2007). Protective effect of Operculina turpethum against7, 12 dimethylbenz (a) anthracene induced oxidative stress with reference to breast Cancer in experimental rats. Chemico-Biological Interactions 168 (3): 229-236. [DOI]

Arulselvan, P., Subramanian, S. (2007). Beneficial effects of Murraya koenigii leaves on antioxidant defense system and ultra structural changes of pancreatic -cells in experimental diabetes in rats. Chemico-Biological Interactions, 165 (2): 155-164. [DOI]

Fang, X., Shao, L., Zhang H, Wang S. (2005). CHMIS-C: a comprehensive herbal medicine information system for 
cancer. Journal of Medicinal Chemistry, 48 (5): 1481-1488. [DOI]

Grover, J.K., Yadav, S., Vats, V. (2002). Medicinal plants of India with anti-diabetic potential, Journal of Ethno pharmacology, 81(1): 81-100. [DOI]

Grover, J.K., Vats, V., Rathi, S.S. (2000). Anti-hyperglycemic effect of Eugenia jambolana and Tinospora cordifolia in experimental diabetes and their effects on key metabolic enzymes involved in carbohydrate metabolism. Journal of Ethno pharmacology 73 (3) 461-470. [DOI]

Harisons principles of internal medicine. (2007). $17^{\text {th }}$ edition., $2275-77$

Holman, R.R., Turner, R.C. (1991). Oral agents and insulin in the treatment of NIDDM, In. J. Pickup And G. Williams, Editors, Text Book of Diabetes, Blackwell, Oxford, 467-469.

Jain, S.K. (1977). Medicinal plants, Director in charge, Botanical Survey of India, 105-107.

John, A., Parrotta. (2005). Healing plants of Penisular India. USDA Forest service, International Institute of Tropical Forestry; 239-251.

Kar, D., Maharana, L., Pattnaik, S., Dash, G. (2006). Studies on hypoglycaemic activity of Solanum xanthocarpum Schrad. \& Wendl. Fruit extract in rats. Journal of Ethnopharmacology, 108 (2): 251-256. [DOI]

Kesari, A.N., Gupta, R.K., Watal, G. (2005). Hypoglycemic effects of Murraya koenigiion normal and alloxan diabetic rabbits, J. Ethnopharmacol, 97 (2): 247-251. [DOI]

Khare, A.K., Srivastava, M.C., Tewari, J.P., Puri, J.N., Singh, S., Ansari, N. A. (1982). A preliminary study of AntiInflammatory activity of Ipomoea turpethum (nishoth).Indian drugs, P.P. 224-228,

Md. Harun-or-Rashid, Gafur, M.A., Md. GolamSadik, Md. Aziz Abdul Rahman. (2002). Antibacterial and Cytotoxic Activities of Extracts and Isolated Compounds of Ipomoea turpethum. Pakisthan Journal of Biological Sciences 5(5): 597-599.
Prakasam, A., Sethupathy, S., Pugalendi, K. (2003). Effect of Casearia esculenta root extract on blood glucose and plasma antioxidant status in streptozotocin diabetic rats. Polish Journal of Pharmacology, 55 (1): 43-49.

Rajashekar, M., Bhande, Laakshmayya, Pramod Kumar, Nitin, K., Mahukar Ramachandra Setty, S. (2006). Pharmacological Screening of Root of Operculina turpethum and its formulations. Acta Pharmaceutica Sciencia 48: 11-17.

Rang, H.P., Dale, M.M. (1991). The Endocrine System Pharmacology, $2^{\text {nd }}$ ed., 504-/508.

Riaz Ahmad, Sarfaraz Ahmed, Nizam Uddin Khan, Absar-ul Hasnain. (2009). Operculina turpethum Attenuates Nnitrosodimethylamine induced toxic liver injury and Clastogenicity in rats. Chemico Biological Interactions 181(2): 145-153. [DOI]

Singh, S.K., Rai, P.K., Jaiswal, D., Watal, G. (2008). Evidencebased critical evaluation of glycemic potential of Cynodon dactylon. Evid. Based Complement Alternat. Med 5 (4): 415-420. [DOI]

Suresh Kumar, S.V., Sujatha, C., Shymala. (2006). Protective effect of root extract of Operculina turpethum Linn. Against Paracetamol induced Hepatotoxicity in rats. Indian Journal of Pharmaceutical Sciences, 68: 32-35. [DOI]

The Ayurvedic pharmacopoeia of India. (2001). $1^{\text {st }}$ edition volume I, part-I, 137.

Tiwari, A.K., Madhusudanarao, J. (2002). Diabetes mellitus and multiple therapeutic approaches of phytochemicals: present status and future prospects, Curr. Sci, 83: 30-38.

World Health Organization. (2008). Traditional Medicine, Fact sheet No. 134. 